\title{
CARACTERIZAÇÃO E ANÁLISE DO PATRIMÔNIO ARBÓREO DA MALHA VIÁRIA URBANA CENTRAL DO MUNICÍPIO DE SÃO CARLOS-SP
}

\author{
Nivia Maria Sucomine ${ }^{1}$; Almir Sales ${ }^{2}$
}

(recebido em 11.01.2010 e aceito para publicação em 15.12.2010)

\section{RESUMO}

O objetivo do presente trabalho foi analisar a arborização viária da área central de São Carlos. Para tal, foi realizado um levantamento quali-quantitativo da cobertura arbórea. Foram encontradas 103 espécies botânicas num total de 2626 indivíduos, sendo que as espécies mais abundantes foram a $S$. molle L. e a M. paniculata (L.) Jacq. Os índices de diversidade e de indivíduos por quilometragem de rua foram respectivamente 3,18 e 26,73 e, o DAP médio foi de $21,4 \mathrm{~cm} ; 45 \%$ da população eram nativas; $55 \%$ apresentaram altura menor que 5,40m e 26 espécies eram frutíferas. Foi identificado um pequeno número de plantas acometidas de injúria ou fitossanidade. Dentre todos os indivíduos, 899 estão em conflito com um ou mais equipamento em entorno, sendo a fiação aérea a principal, e $76 \%$ possuíam pouco ou nenhum espaço livre de pavimentação. Por meio dos resultados obtidos, concluiu-se que a composição florística dessa área é bem diversa. Em termos quantitativos, essa população pode ser classificada como muito deficiente, apesar do estado satisfatório da maioria das árvores.

Palavras-chave: arborização viária, inventário, banco de dados.

\footnotetext{
${ }^{1}$ Ecóloga, Mestranda do Programa de Pós-Graduação em Engenharia Urbana, PPGEU/UFSCar. São Carlos, SP. E-mail: niviasucomine@hotmail.com

${ }^{2}$ Engenheiro Civil, Prof. Dr. do Departamento de Engenharia Civil da UFSCar. São Carlos, SP. E-mail: almir@power.ufscar.br
} 


\section{DESCRIPTION AND ANALYSIS OF THE TREE HERITAGE IN THE URBAN STREETS OF SAO CARLOS' DOWNTOWN AREA}

\section{ABSTRACT}

This research aimed to analyze the street tree planting of Sao Carlos' downtown area. For doing this, a qualitative and quantitative survey of the tree cover was carried out. A total of 2,626 individuals distributed in 103 botanical species was found and the most abundant ones were S.molle L. and M. paniculata (L.) Jacq. The diversity index and the average index of trees per kilometer of street were 3.18 and 26.73 respectively, as the average DBH was 21.4 $\mathrm{cm} ; 45 \%$ of the population was composed of native species, $55 \%$ had height less than 5.40 $\mathrm{m}$, and 26 species were fruit trees. Few individuals were affected or injured. However, among all individuals 899 were in conflict with one or more urban equipments, especially electric light wiring, and $76 \%$ had little or no space without pavement. These results led us to conclude that the floristic composition in this area is a rich one. From a quantitative view, this population may be classified as very deficient, despite the satisfactory overall status of most of the trees.

Keywords: street tree planting, inventory, database. 


\section{INTRODUÇÃO}

O ser humano, por muito tempo, conseguiu manter um equilíbrio em suas relações com o ambiente. Contudo, devido ao aumento da população humana e o advento da industrialização houve um grande fluxo de pessoas do campo para as cidades que, por falta de um planejamento, cresceram desordenadamente, tornando-as ineficientes na promoção de qualidade de vida aos seus citadinos.

Diversas pesquisas da área do urbanismo, clima, paisagismo e agronomia, visando restabelecer o bem-estar outrora perdido, consideraram por unanimidade a arborização urbana como um fator essencial para a melhoria dessa qualidade, dada sua capacidade de mitigar ou amenizar os efeitos antropogênicos (reduzem o calor e a poluição atmosférica e sonora; diminuem a velocidade dos ventos; produzem sombra; evitam enchentes; contribuem para a formação das nuvens; embelezam ruas; protegem o solo; atraem a avifauna, dentre outros).

A arborização, apesar de sua relevância, encontra-se hoje reduzida a meros fragmentos remanescentes sufocados em meio à malha urbana, uma vez que é vista como uma atividade esteticamente desejada, mas não necessariamente prioritária.

Nesse aspecto, abre-se espaço a iniciativas particulares pontuais em realizar o plantio de árvores que, desprovidos de um conhecimento técnico-científico sobre o assunto, dão aos locais destinados à arborização um aspecto irregular, descontínuo e inadequado, gerando muitas inconveniências e prejuízos tanto ao poder público quanto à população.

Como consequência dessa inadequação, a arborização empreendida mostra-se também ineficaz, pois os benefícios que esta poderia, potencialmente, proporcionar à comunidade, não são observados (BORTOLETO, 2004).

Entretanto, de acordo com Kuchelmeister e Braatz (1993), a arborização urbana pressupõe as atividades de planejamento, implantação e manutenção sob o poder público e que deveria fazer parte dos serviços essenciais de uma cidade, seu planejamento deveria atender aos objetivos predeterminados e ser continuamente avaliado e controlado, a fim de corrigir imediatamente eventuais falhas de manejo. 
Contudo, segundo Pivetta e Silva Filho (2002), quando não é possível planejar, é importante, no mínimo, analisar a arborização já existente, permitindo conhecer a condição da arborização em termos de adaptabilidade e problemas relacionados à espécie e às condições de plantio para que alguma providência técnica seja tomada. A análise da arborização pode ser realizada por meio de um inventário.

Nesse sentido, o presente trabalho teve como objetivos:

- Descrever e avaliar a diversidade, distribuição e composição das espécies arbóreas contidas na malha viária central urbana do município de São Carlos, SP;

- Identificar a situação real desse patrimônio arbóreo.

\section{MATERIAL E MÉTODOS}

\section{Caracterização da área de estudo}

O estudo foi realizado no município de São Carlos, localizado na região central do estado de São Paulo, situado a 47 53' 38" Longitude Oeste e $22^{\circ} 01^{\prime}$ '22" Latitude Sul, distante $231 \mathrm{~km}$ da capital. A área total do município é de $1.140,92 \mathrm{~km}^{2}$, sendo $67,25 \mathrm{~km}^{2}$ de área urbana (SEADE, 2007).

O levantamento da arborização abordou todas as vias públicas inseridas na área central urbana do município de São Carlos, pertencentes ao primeiro período de expansão e evolução da cidade, cujos limites podem ser observados na Figura 1. Esse local foi eleito como área de coleta de dados por apresentar um estado bastante crítico quanto à arborização e por ser um espaço de intenso tráfego tanto de pessoas quanto de veículos. 


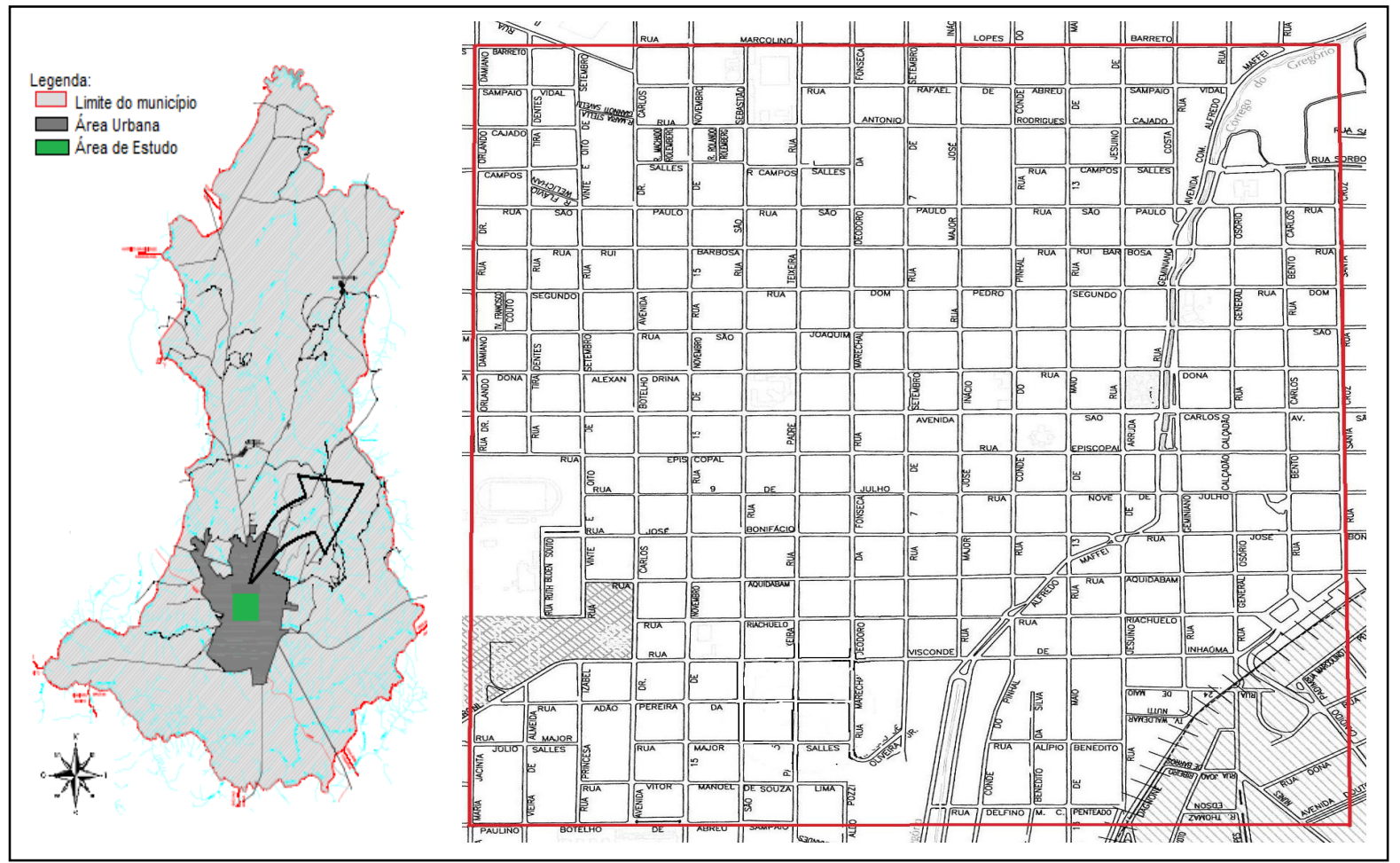

Fonte / Source: Secretaria de Habitação-PMSC, 2003 (escala 1:60.000).

FIGURA 1. Mapa do Município de São Carlos com destaque a área de estudo.

FIGURE 1. Map of the town of Sao Carlos highlighting the study area.

\section{Inventário da arborização viária}

Foi realizado um inventário total (catalogação de toda população) dos indivíduos vegetais de porte arbóreo e arbustivo presentes nas calçadas das ruas abrangidas, excetuando-se as áreas verdes e canteiros centrais.

Os dados foram coletados no período de outubro a dezembro de 2008, e anotados em um formulário de registro de formato tabular, com utilização de códigos (Figura 2), cuja confecção foi baseada nos parâmetros quali-quantitativos sugeridos em trabalhos anteriores dentre os principais Andrade (2002), Grey e Deneke (1986), Lima (1993), Santos (2001), Silva Filho (2002), Silva et al. (2008), adaptados à realidade e necessidade da pesquisa. 


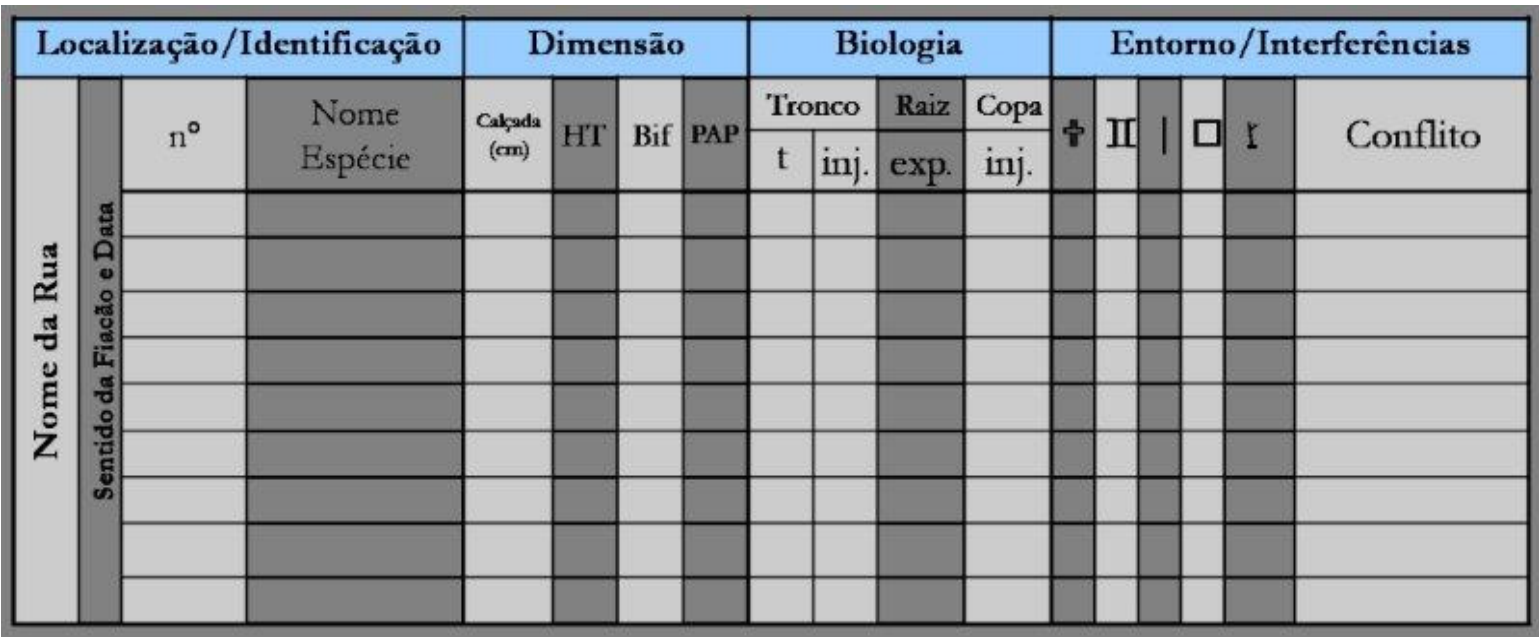

Sendo:

$\mathrm{n}^{\circ}$ : número da casa mais próxima à árvore; $\mathrm{HT}$ : altura total; $\mathrm{H} 1^{\circ} \mathrm{Bi}$ : altura da primeira bifurcação; PAP: perímetro do tronco à altura do peito; Tronco: $t$ (tortuosidade), inj. (injúria tipo: 1. Fitossanidade ou 2. Inj. Mecânica; Grau: 1. Grave, 2. Médio ou 3. Leve); Raiz: exp. (exposta ou não, caso positivo identificar tipo e grau de injúria, se houver); Copa: inj. (tipo e grau da injúria); ‡̧: árvore morta; II: Gradil; | : Tutor; $\square$ : Área de infiltração (Nulo: sem espaço,

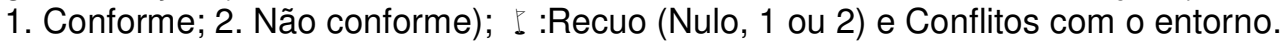

FIGURA 2. Formulário de campo para coleta de dados.

FIGURE 2. Field data collection form.

Uma vez finalizadas as saídas de campo, iniciou-se a etapa de inserção dos dados manuais (provenientes dos formulários do levantamento quali-quantitativo) para um ambiente eletrônico.

O programa escolhido para tabulação, tratamento e análise dos dados foi o sistema de gerenciamento de banco de dados (SGBD) Microsoft ACCESS para Windows 2007, e a elaboração da estrutura do banco de dados seguiu os procedimentos de Dalcin (1994); Takahashi (1992) e Silva Filho (2002).

\section{RESULTADOS E DISCUSSÃO}

No levantamento quali-quantitativo da arborização viária localizada na região central da cidade de São Carlos (SP), foi identificado nos 107.806 metros de ruas percorridas, um total de 103 espécies vegetais, pertencentes a 78 gêneros distintos e distribuídos em 44 famílias botânicas. 
$\mathrm{Na}$ área urbana de São Carlos, embora tenha sido encontrado um número total relativamente alto de diversidade de espécies, a grande maioria (57) possuiu no máximo quatro indivíduos por espécie, sendo 20 delas representadas somente por dois exemplares e 22 representadas apenas por um único exemplar, como foi o caso do algodoeiro, rosa de jericó, cheflera, flamboyam, ipê roxo de sete folhas, santa bárbara, bracatinga e pinheiro de buda.

A baixa frequência de indivíduos por espécie demonstrou que boa parte dos plantios foi feita por iniciativa da própria população. Esta ação contribuiu para o incremento da diversidade local, mas por outro lado prejudicou o planejamento.

Do total das 2626 árvores catalogadas, 147 foram consideradas árvores mortas. Estas corresponderam a 5,6\% da população total.

Com os dados dos 2479 indivíduos encontrados vivos, foi elaborada uma tabela (Tabela 1) que apresenta a distribuição quantitativa das espécies mais abundantes encontradas na arborização viária do local de estudo.

Segundo Grey e Deneke (1986), o valor mínimo de espécies a serem utilizadas para compor de forma homogênea a arborização de uma cidade seria de 7 a 10. Nesse enfoque, por meio da análise da Tabela 1, constatou-se que a soma das 10 primeiras espécies listadas constituiu $70,6 \%$ da população vegetal, indicando uma equidade regular.

No entanto, seria importante diminuir a incidência da espécie dominante (Schinus molle L.), por meio da promoção do plantio de outras espécies de menor freqüência, por exemplo: magnólia, alfeneiro, oiti, quaresmeira, melaleuca, pata-de-vaca e todas as espécies do gênero dos ipês (amarelo, branco, rosa, roxo, etc.).

Foi verificado na área de estudo um índice de diversidade igual a 3,18, de acordo com a expressão proposta por Shannon-Weiner $\left(\mathrm{H}^{\prime}\right)$, que considera riqueza e abundância.

A partir dos dados inventariados, foi calculado o índice de indivíduos por quilometragem de rua para cada uma das 47 vias públicas percorridas.

A Rua Alípio Benedito foi a que possuiu o maior índice: 79,03; seguida pela Rua Major José Inácio: 48,20; e a travessa Waldemar Nutti: 45,26. Em contrapartida, encontrouse entre as ruas menos arborizadas a Avenida São Carlos, Rua Episcopal e Rua Quinze de Novembro, cujos valores foram respectivamente 5,76, 9,09 e 9,22. O índice médio foi igual a 26,73 . 
TABELA 1. Frequência relativa das espécies mais abundantes encontradas na arborização viária da zona central urbana de São Carlos.

TABLE 1. Relative frequency of most abundant species in the streets tree planting of Sao Carlos' downtown area.

\begin{tabular}{cccc}
\hline Nome vulgar & Nome científico & Total & $\begin{array}{c}\text { Frequência } \\
(\%)\end{array}$ \\
\hline Alfeneiro & Ligustrum lucidum W. T. Aiton & 83 & 3,3 \\
Aroeira salsa & Schinus molle L. & 437 & 17,2 \\
Cana fístula & Cassia fistula L. & 20 & 0,8 \\
Chapéu de sol & Terminalia catappa L. & 23 & 0,9 \\
Escova de garrafa & Callistemon imperialis & 20 & 0,8 \\
Escova de garrafa & Callistemon viminalis (Sol. ex & 51 & 2,1 \\
pendente & Gaertn.) G. Don ex Loud. & 31 & 1,3 \\
Espirradeira & Nerium oleander L. & 355 & 14,3 \\
Falsa murta & Murraya paniculata (L.) Jacq. & 21 & 0,9 \\
Figueira benjamina & Ficus benjamina L. & 1,4 \\
Flamboyam de jardim & Caesalpinia pulcherrima (L.) Sw. & 34 & 2,8 \\
Ipê amarelo & Handroanthus ochraceus (Cham.) & 69 & 1,0 \\
Ipê amarelo de & Mattos & 25 & 1,7 \\
jardim & Tecoma stans (L.) Juss. ex Kunth & 25 & \\
Ipê branco & Handroanthus roseo-albus (Ridl.) & 42 & 3,8 \\
Jerivá & Mattos & 95 & 3,6 \\
Magnólia amarela & Syagrus romanzoffiana (Cham.) & 95 & 1,1 \\
Manacá da serra & Glassman & 239 & 9,6 \\
Melaleuca & Michelia champaca L. & 39 & 1,6 \\
Oiti & Melaleuca linariifolia Sm. Sm. & 33 & 1,3 \\
Pata de vaca & Licania tomentosa (Benth.) Fritsch & 78 & 3,2 \\
Quaresmeira & Bauhinia variegata L. & 81 & 3,3 \\
Resedá & Tibouchina granulosa (Desr.) & 64 & 2,6 \\
Saboneteiro & Cogn. & 206 & 8,3 \\
Sibipiruna & Lagerstroemia indica L. & 26 & 1,1 \\
\hline & Sapindus saponaria L. & 119 & 4,8 \\
\hline
\end{tabular}

Segundo Silva Filho (2002), o valor recomendado desse índice é de 200 árvores por quilômetro de rua, esse dado permite estimar para a área central da cidade de São Carlos um déficit total de 18935 árvores.

De todos os vegetais encontrados nas calçadas das vias públicas da área de estudo, foram cadastrados 502 mudas, representando 19,1\% da população, quantidade considerada significativa.

As médias da altura total e da altura da primeira bifurcação foram de 1,45 m e $87 \mathrm{~cm}$, respectivamente. Estes valores estão bem abaixo do padrão recomendado de 2,50 m e 1,80 
m, respectivamente. Em relação ao DAP, somente $31,3 \%$ das mudas inventariadas possuíam um valor igual ou superior ao estipulado (três centímetros). Essa situação reflete a baixa qualidade das mudas produzidas e a falta de poda de condução.

Além disso, a grande maioria das mudas não possuía gradil de proteção (86,5\%), recuo do meio fio viário $(69,9 \%)$ e pouco ou nenhuma área livre adequada à futura dimensão que o tronco atingirá $(66,9 \%)$. No entanto, 67,7\% dessa população apresentaram tutor de condução bem ajustados; $89,4 \%$ das mudas foram plantadas em conformidade com a distância mínima estabelecida a qualquer tipo de equipamento urbano; e 98,4\% mostraram ter um bom desenvolvimento da parte aérea, sem problemas de enraizamento ou de injúrias.

Em relação à altura total das árvores vivas adultas (1977 indivíduos), 55\% das plantas utilizadas para a arborização viária ao longo das calçadas, na área de estudo, estavam abaixo da fiação telefônica $(5,40 \mathrm{~m})$ e apenas $4 \%$ ficavam acima da fiação elétrica de alta tensão $(9,10 \mathrm{~m})$.

A média encontrada para os diâmetros à altura do peito (DAP) foi de $21,4 \mathrm{~cm}$, indicando uma arborização formada, preponderantemente, por indivíduos jovens.

Em relação à altura da primeira bifurcação $(\mathrm{Hb})$, a média encontrada foi de 1,5 $\mathrm{m}$, um valor aquém do ideal estabelecido (2,10 m). Na área estudada, 1096 indivíduos (55,4\% da população) não atingiram esse valor. Apesar da elevada porcentagem, apenas 104 deles $(5,3 \%)$ interferiam no livre trânsito de pedestres e/ou de veículos. Essa comunidade, formada essencialmente por espécies de M. paniculata (L.) Jacq. e L. indica L., reflete uma constante necessidade de manutenção por parte da prefeitura local (podas de condução e correção de erros de má formação).

De toda comunidade cadastrada da arborização viária da região central de São Carlos, constatou-se que 55,5\% dela é composta por espécies exóticas.

Das 103 espécies cadastradas 26 foram plantas fornecedoras de frutos comestíveis ao homem, entre elas Licania tomentosa (Benth.) Fritsch (oiti) e Syagrus romanzoffiana (Cham.) Glassman (jerivá), onde juntas somaram 73\% do total da população de frutíferas.

A avaliação da integridade física e sanitária da população adulta inventariada foi realizada por meio da análise dos dados qualitativos coletados (Tabela 2) das principais partes formadoras da árvore: o tronco, a raiz e a copa.

De modo geral, do total de árvores adultas inventariadas, foi alta a frequência de indivíduos que não apresentaram qualquer tipo de lesão sanitária (ataques de patógenos, 
pragas e/ou parasitas) e/ou mecânica (causadas por vandalismo, fenômenos naturais, acidentes, podas mal gerenciadas e/ou pisoteio de raízes).

TABELA 2. Frequência relativa dos diferentes graus de severidade das injúrias identificadas no tronco, na raiz e na copa ( $\mathrm{A}$ : injúria mecânica, $\mathrm{B}$ : fitossanidade).

TABLE 2. Relative frequency of different degrees of severity of the injuries identified in the trunk, root, and crown (A: mechanical injury, B: phytosanity).

\begin{tabular}{|c|c|c|c|c|c|c|}
\hline \multirow{2}{*}{$\begin{array}{c}\text { Grau de } \\
\text { severidade }\end{array}$} & \multicolumn{2}{|c|}{ Tronco } & \multicolumn{2}{c|}{ Raiz } & \multicolumn{2}{c|}{ Copa } \\
\cline { 2 - 7 } & A & B & A & B & A & B \\
\hline Sem dano & $90,1 \%$ & $91,5 \%$ & $93,7 \%$ & $95,9 \%$ & $74,5 \%$ & $90,5 \%$ \\
\hline Dano Leve & $4,8 \%$ & $3,0 \%$ & $3,9 \%$ & $0,8 \%$ & $11,4 \%$ & $3,5 \%$ \\
\hline Dano Médio & $3,4 \%$ & $3,6 \%$ & $1,8 \%$ & $0,8 \%$ & $8,7 \%$ & $3,6 \%$ \\
\hline Dano Grave & $1,7 \%$ & $1,9 \%$ & $0,7 \%$ & $2,4 \%$ & $5,4 \%$ & $2,4 \%$ \\
\hline
\end{tabular}

A seguir, discutem-se as variáveis relacionadas à caracterização do espaço físico e dos equipamentos urbanos presentes no entorno do local onde o indivíduo arbóreo está inserido.

Foi encontrado um valor médio de 2,30 m para a largura dos passeios presentes na área central da cidade de São Carlos. Quanto ao espaço livre de impermeabilização junto ao tronco, foi detectado que 30,3\% das plantas tinham pouquíssimas ou nenhuma área livre, sendo que 46,4\% tinham uma pequena área e 23,1\% delas possuíam uma boa área livre. Em relação à distância da árvore ao meio fio viário, apenas $20 \%$ de todos os indivíduos analisados apresentaram algum distanciamento ao meio fio.

Ademais, das 1977 árvores adultas estudadas, 899 (mais de 45\% da população total) apresentaram um ou mais conflito com o entorno. Os tipos e suas frequências podem ser observados na Tabela 3.

Foi realizado para a área de estudo uma hierarquização dos indivíduos conforme a necessidade de manejo. Sob esse aspecto, a arborização viária apresentou-se em um nível satisfatório, sendo que apenas três indivíduos se encontravam em avançado estágio de declínio, e outros 125 indivíduos foram identificados com indício de declínio e problemas fisiológicos requerendo reparo. A grande maioria, $84,7 \%$ da população amostrada, encontrou-se em boa condição de saúde e vigor, necessitando de pequenos reparos, sendo que os demais, 174 indivíduos (8,8\% da população), foram plantas vigorosas e sadias. 
TABELA 3. Tipos e frequência dos conflitos da arborização viária central de São Carlos.

TABLE 3. Types and frequency of conflicts in the streets tree planting of Sao Carlos' downtown area.

\begin{tabular}{|c|c|c|}
\hline Tipo de conflito & $\begin{array}{c}\text { Total de } \\
\text { indivíduos }\end{array}$ & Frequência \\
\hline Copa em contato com fiação aérea & 370 & $18,7 \%$ \\
\hline Raiz danifica o calçamento & 333 & $16,8 \%$ \\
\hline Mais de um vegetal no local de plantio & 186 & $9,4 \%$ \\
\hline Vegetal atrapalha a passagem de pedestre & 103 & $5,2 \%$ \\
\hline Planta próxima a garagem & 99 & $5 \%$ \\
\hline Vegetal atrapalha trânsito & 57 & $2,9 \%$ \\
\hline Planta próxima a poste de iluminação & 33 & $1,7 \%$ \\
\hline Outros (lixeira, esquina, bueiro etc.) & 45 & $2,3 \%$ \\
\hline
\end{tabular}

Vale salientar que os resultados de integridade física e de compatibilidade dos vegetais com o entorno atingiram níveis aceitáveis e satisfatórios, sendo que isto deve estar relacionado ao fato da arborização analisada ser formada basicamente por indivíduos jovens e mudas que ainda não atingiram o pleno desenvolvimento de suas copas e raízes. Este fato contribuiu para reduzir os conflitos com a fiação e com o calçamento, considerados incipientes e, desta forma minimizou os problemas de implantação e a necessidade de correções essenciais para o planejamento.

\section{CONCLUSÕES}

Na composição florística da arborização viária da região central urbana de São Carlos existe um número muito grande de espécies representadas por apenas um único exemplar e muitos indivíduos de poucas espécies (S. molle e M. paniculata). No entanto, segundo os valores médios referente aos índices de árvores por quilômetro de rua, em termos quantitativos, essa população é ainda muito deficiente.

As mudas recém-plantadas apresentaram, em geral, características morfológicas que comprometem a sua sobrevivência e crescimento em seu local de plantio, porém momentaneamente, a falta de conformidade da muda com tais fatores não vem interferindo em seu desenvolvimento, uma vez que suas condições físicas e fitossanitárias apresentaram-se satisfatórias. Em relação à altura e o DAP do restante da população, os resultados obtidos indicaram uma arborização com predomínio de árvores jovens. 
De modo geral, sobre avaliação dos demais aspectos qualitativos (danos físicos, injúrias, doenças, conflitos etc.), julgou-se a situação das árvores da área de estudo ser bem satisfatória, visto a grande quantidade de árvores que necessitam de pouco ou nenhum reparo.

\section{AGRADECIMENTOS}

Os autores agradecem a CAPES e ao MCT/CNPq pelos recursos financeiros aplicados no desenvolvimento desta pesquisa.

\section{REFERÊNCIAS BIBLIOGRÁFICAS}

ANDRADE, T. O. Inventário e análise da arborização viária da estância turística de Campos do Jordão, SP. 2002. 112 f. Dissertação (Mestrado) - Escola Superior de Agricultura "Luiz de Queiroz", Universidade de São Paulo, Piracicaba, 2002.

BORTOLETO, S. Inventário quali-quantitativo da arborização viária da Estância de Águas de São Pedro-SP. 2004. 85 f. Dissertação (Mestrado em Agronomia). Escola Superior de Agricultura “Luiz de Queiroz", Universidade de São Paulo, Piracicaba, 2004.

DALCIN, E. C. A informática no inventário e monitoramento da arborização urbana. In: CONGRESSO BRASILEIRO SOBRE ARBORIZAÇÃO URBANA, 2., 1994, São Luís. Anais... São Luís: Sociedade Brasileira de Arborização Urbana, 1994. p. 201-206.

GREY, G. W.; DENEKE, F. J. Urban forestry. New York: John Wiley \& Sons, 1986. 279 p. KUCHELMEISTER, G.; BRAATZ, S. Urban forestry revisited. Unasylva, v. 44, n. 173, p. 3$12,1993$.

LIMA, A. M. L. P. Piracicaba/SP: análise da arborização viária na área central e em seu entorno. 1993. 238 f. Tese (Doutorado em Agronomia) - Escola Superior de Agricultura "Luiz de Queiroz", Universidade de São Paulo, Piracicaba, 1993.

PIVETTA, K. F. L.; SILVA FILHO, D. F. Arborização urbana. Jaboticabal: Unesp/FCAV/FUNEP, 2002. (Boletim Acadêmico. Série Arborização Urbana).

SANTOS, E. Avaliação quali-quantitativa da arborização e comparação econômica entre a poda e a substituição da rede de distribuição de energia elétrica da Região Administrativa Centro-Sul de Belo Horizonte-MG. 2001. 219 f. Tese (Doutorado em Ciência Florestal) - Universidade Federal de Viçosa, Viçosa, 2001. 
Sistema estadual de ANÁlise DE DADOS - SEADE. Perfil Municipal de São Carlos. 2007. Disponível em: <http://www.seade.gov.br/produto/perfil/perfil.pdf>. Acesso em: 24 jun. 2009.

SILVA FILHO, D. F. Cadastramento informatizado, sistematização e análise da arborização das vias públicas do município de Jaboticabal, SP. 2002. $81 \mathrm{f}$. Dissertação (Mestrado em Agronomia) - Faculdade de Ciências Agrárias e Veterinárias, Universidade Estadual Paulista, Jaboticabal, 2002.

SILVA, M. D. M.; SILVEIRA, R. P.; TEIXEIRA, M. I. J. G. Avaliação da arborização de vias públicas de uma área da região oeste da cidade de Franca/SP. Revista da Sociedade Brasileira de Arborização Urbana, v. 3, n. 1, p. 19-35, 2008.

TAKAHASHI, L. Y. Sistema informatizado de manejo da arborização de ruas. In: CONGRESSO BRASILEIRO SOBRE ARBORIZAÇÃO URBANA, 1., 1992, Vitória. Anais... Vitória: PMV/SMMA, 1992. p. 281-290. 